\title{
Latin-American guidelines for cancer pain management
}

Argelia Lara-Solares ${ }^{*}$, , Marisol Ahumada Olea ${ }^{2}$, Amparito de los Ángeles Basantes

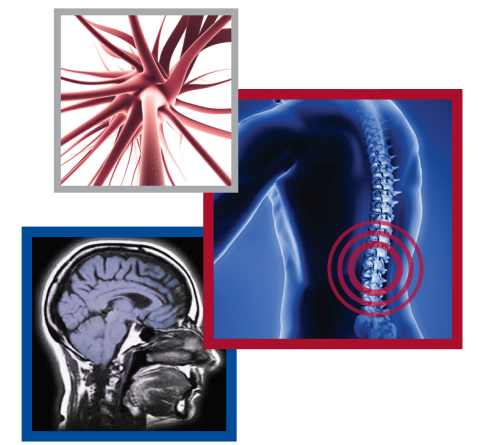
Pinos $^{3}$, Sara Bistre Cohén ${ }^{4}$, Patricia Bonilla Sierra ${ }^{5}$, Eva Rossina Duarte Juárez ${ }^{6}$, Omar A Símon Escudero7, Juan Guillermo Santacruz Escudero ${ }^{8}$ \& José Alberto Flores Cantisani ${ }^{9}$

\section{Practice points}

- Adequate pain management starts with an appropriate syndromic diagnosis based on a detailed clinical history, comprehensive physical examination and correct interpretation of additional medical tests.

- Appropriate syndromic classification of pain is based on its clinical characteristics, as well as on a meticulous assessment of the intensity of pain by applying standard scales. The patient's psychosocial situation must be taken into account when attempting to optimize management and predict the response to treatment.

- As with all types of chronic pain, assessment of patients with cancer pain should take into account the individual profile of the patient (age, comorbidities, functionality, previous exposure to drugs such as opioids and polypharmacy) and the type, intensity and potential clinical course of the pain. Only thus will it be possible to decide on the best approach, based on aspects such as efficacy, safety, tolerability and cost. Multimodal strategies are the most successful.

- Multimodal approaches include interventional, psychological, rehabilitative and integrative therapies.

- Various formulations of fentanyl have been reported for the treatment of breakthrough pain, as follows: transmucosal, intranasal, sublingual, buccal tablets and gingival. However, these formulations are not available in Latin America.

- In Latin America, the WHO guidelines have proven critical for justifying to local governments the key role of opioids such as morphine and the need for an adequate supply. Nevertheless, availability of opioids in the region remains poor.

- Treatment of severe pain should be with a strong opioid, in most cases with oral formulations. Other routes (intravenous, subcutaneous, spinal (epidural and intrathecal) may only be necessary in refractory cases.

- Extended-release opioids (morphine, oxycodone and hydromorphone) can be supplemented with immediate-release formulations as needed. Assessment of comorbidities is essential when deciding on the best option.

'Department of Pain Medicine \& Palliative Care, Instituto Nacional de Ciencias Médicas y Nutrición 'Salvador Zubirán', Mexico City, Mexico

${ }^{2}$ CR Alivio Dolor \& CP INCANCER, Asociación Chilena para el Estudio del Dolor (ACHED), Asociación Latino Americana de Cuidados Paliativos (ALCP), Santiago de Chile, Chile

${ }^{3}$ Departmentof Oncology, Hospital Metropolitano, Quito, Ecuador

${ }^{4}$ Health Science, Universidad Anáhuac del Norte, Mexico, DF, Mexico

${ }^{5}$ Pain \& Palliative Service, Instituto Medico La Floresta, Caracas, Venezuela

${ }^{6}$ Palliative Care \& Symptoms Control Service, Institutode Cancerología, Palliative Medicine Unit, Hospital 'Nuestra Señora del Pilar', GuatemalaCity, Guatemala

7Department of Oncolgy, Surgical Oncology Service, Hospital Nacional 'Daniel Alcides Carrión', Cancer Pain Therapy and Palliative Care, ADAMO (Atención Ambulatoria del Adulto Mayor y Paciente Oncológico), Dirección Regional de Salud (DIRESA) Callao, Lima, Perú

${ }^{8}$ Pain \& Palliative Service, Hospital Universitario Fundación Santa Fe. Bogotá, Colombia

${ }^{9}$ Programa Regional de Cuidados Paliativos, Unidad Médica de Alta Especialidad No. 25, IMSS, Monterrey NL, México

*Author for correspondence: Tel.: +52 555487 0900, ext. 5011; argelia.lara@dolorypaliativos.org

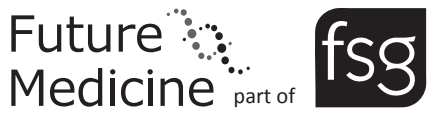


Practice points (cont.)

- Nausea as an adverse effect of opioids usually appears at initiation of treatment and is transient; therefore, antiemetics should only be prescribed when strictly necessary. Constipation can be managed with dietary interventions, hydration and laxatives.

- Opioids can be rotated to improve analgesia and/or diminish adverse effects. Decisions should be taken based on equianalgesic tables.

- Cancer pain can also be managed using interventional therapy and psychological, rehabilitative and integrated approaches.

\section{KEYWORDS \\ - analgesics • cancer pain \\ - Latin America • opioids \\ - pain control}

Cancer is a major public health issue. Poor pain management has devastating consequences that seriously affect quality of life, diminish functionality and place a huge emotional burden on patients and their relatives. A group of Latin American opinion leaders were invited to participate in a meeting to discuss areas associated with cancer pain. The expert panel reviewed the latest literature to draft region-specific guidelines for effective pain management. The guidelines make recommendations on tailoring treatment to the specific type of pain and provide local physicians with the state-of-the art findings in the field. Management should be with pharmacological approaches (nonopioid, adjuvant and opioid analgesics, as well as oncologic therapies and interventional procedures) and nonpharmacological approaches.

First draft submitted: 25 January 2017; Accepted for publication: 15 February 2017; Published online: 13 March 2017

Cancer is a major public health issue in Latin America and the Caribbean. It is estimated that by 2030 , approximately 1.7 million people will have been diagnosed with cancer in the region and that more than 1 million people per year will die from the disease. Consequently, major difficulties will arise when addressing the increasing morbidity and mortality associated with the disease, especially in advanced stages [1], in a region characterized by major population growth under unfavorable conditions, such as widespread poverty, persistent and severe social inequality, scarce institutional development and poor social security [2].

Pain is one of the most overwhelming symptoms of cancer. According to a meta-analysis by van den Beuken-van Everdingen et al. [3], the prevalence of cancer pain ranges from 43 to $63 \%$ at all stages of the disease, 59\% (average) in patients undergoing treatment for cancer, up to $70 \%$ in patients with advanced or terminal disease and 33\% in survivors [3].

Pain is the most feared symptom for patients and their families. Despite international efforts to improve pain control, much remains to be done. Poor pain management has devastating consequences, seriously affects quality of life, diminishes functionality and places a huge emotional burden on patients and their relatives.
Inadequate pain management is a result of several factors, such as the biological behavior of the tumor itself, specific patient features, lack of knowledge about indications and prescription of opioids by health professionals and fear of adverse effects and addiction to opioids, all of which lead to restrictive health regulations governing strong analgesics. Therefore, any major change would call for major changes in specific areas [1].

Since pain can be present at diagnosis or before, analgesic treatment should begin when required by the patient. According to current estimations, 5.7 million people have little or no access to opioid analgesics [4].

Opioid consumption in Latin America and the Caribbean is variable. According to international standards, moderate levels of consumption are reported (1-10 $\mathrm{mg}$ of morphine equivalents per capita per year) in Argentina, Chile, Brazil, Colombia, Cuba, Mexico, Costa Rica and Uruguay, as well as in Guatemala, Honduras and Bolivia, where particularly low levels have been recorded [5]. Nevertheless, average consumption remains far below international levels, suggesting that pain management is inadequate for much of the Latin American population [1].

At a meeting held in Antigua, Guatemala (11-14 June 2015) the expert panel Change 
Pain Latin America provided general recommendations to improve diagnosis and explained all the available cancer pain treatments in Latin America, based on the best scientific evidence available at the time.

\section{Classification \& assessment of cancer pain}

Adequate pain management starts with an appropriate syndromic classification. Consequently, obtaining a detailed clinical history, performing a comprehensive physical examination and correct interpretation of the results of paraclinical tests [6] are mandatory when determining the origin, etiology, pathophysiology, intensity, duration and seasonality of pain (Box 1 \& 2) [7].

Furthermore, the patient's characteristics must be considered in order to determine the effect of pain on his/her quality of life, functional impairment and overall psychophysical consequences.

\section{Evaluation of pain}

Given that there is no international consensus on classification of cancer pain and that specific tools are lacking, the conventional scales used for other forms of chronic pain are commonly applied. Thus, appropriate classification of cancer pain is essential if we are to optimize treatment, predict the patient's response, compare results and, ideally, standardize management [6].

\section{Clinical history}

The clinical history is based on an interview to determine personal data (age, gender), tumor diagnosis, disease status, progression, treatments, complications, pre-existing chronic pain and emotional state, as well as whether the patient is adapting to his/her condition and how the disease and pain affect his/her daily life from a physical, emotional and family perspective and in terms of sleep quality and general functioning.

It is important to record previous analgesics, previous medication in general, and the success of these approaches. Additional information that can modify perception of pain should be taken into account, for example, psychiatric history, prior or current aberrant behaviors with respect to opioid consumption and risk factors that may lead to inadequate pain management, such as a history of abuse of alcohol (and other substances), belonging to minority groups (elderly, children, pregnant women, patients with communication disabilities or patients whose
Box 1. Etiology of cancer pain.

\section{Related to cancer}

- Bone lesions:

- Spinal cord compression, metastases in skull base, vertebral fractures, costal fractures, long-bone lesions:

- Nervous infiltration: breasts epidural and meningeal

- Visceral causes: pleural, liver, peritoneal and pancreatic involvement

- Arterial, venous and lymphatic vessel infiltration

\section{Secondary to treatment}

- Postsurgical, post-thoracotomy, postamputation

- Postradiotherapy

- Postchemotherapy

- Mucositis, enteritis, myalgia, arthralgia, neuropathy

\section{Not related to cancer}

- Postherpetic neuralgia

- Diabetic neuropathy

- Arthrosis

- Arthralgia caused by rheumatoid arthritis

- Myofascial pain

Pain in surviving patients

- Postmastectomy

- Post-thoracotomy

- Postamputation

Data taken from $[7,8]$.

spiritual beliefs may affect their perception of pain) [6,12-14].

The interview should include questions about onset of pain, site affected, irradiation and intensity in the previous $24 \mathrm{~h}$ and week, both at rest and in motion. The characteristics and type of pain-nociceptive (pressure, throbbing) and neuropathic (muscle-cramps, colic, visceral pain, burning sensation, electrical current and tingling) should also be recorded, as should attenuating and exacerbating factors, duration, response to analgesics and response to disease modifiers, as well as an evaluation of functional, psychological and social consequences [15].

\section{Physical examination}

A physical examination should be performed at every visit. Neurologic and sensory examinations should also be carried out, including tactile, thermal and pain sensitivity, evaluation of alterations of the autonomic nervous system 
Box 2. Pain classification.

\begin{tabular}{l} 
Duration \\
- Acute \\
- Chronic \\
Pathophysiology \\
- Nociceptive: \\
- Somatic \\
- Visceral \\
- Neuropathic \\
- Combination of the above \\
Type \\
- Continuous or basal \\
- Episodic pain: \\
- Incident \\
- Breakthrough \\
- Pain at the end of the dose \\
Intensity \\
- Mild \\
- Moderate \\
- Severe \\
\hline Data taken from [7-11].
\end{tabular}

and thermoregulation, deep reflexes and cranial nerves. The musculoskeletal system, muscular tropism, muscle tone and involuntary movements should also be assessed.

\section{Pain scales}

Despite the large variety of pain evaluation scales, no instruments have been specifically validated for cancer pain [13]. The most commonly used are shown in Box 3.

\section{One-dimensional scales}

The three scales are equivalent due to their simplicity, clarity and ease of application. Clinical trials have demonstrated that the numerical rating scale is more reliable than the visual analog scale [16]. These scales have limited sensitivity owing to wide interindividual variability and

Box 3. Pain scales.

\begin{tabular}{l} 
One-dimensional \\
- VAS \\
- NRS \\
- VRS \\
Multidimensional \\
- Brief Pain Inventory \\
- McGill Pain Questionnaire \\
- Edmonton staging system for cancer pain \\
\hline NRS: Numerical rating scale; VAS: Visual analog scale; VRS: \\
Verbal rating scale. \\
Data taken from [13,16-17].
\end{tabular}

different emotional, affective, cognitive, cultural and behavioral responses [18].

\section{Multidimensional scales}

Multidimensional scales are more complete because they measure multiple dimensions: sensory (location, intensity, quality and pattern of pain); affective (fear, depression and anxiety related to pain); cognitive (overall appraisal of pain); and behavioral (aggravating and alleviating actions) [19]. These scales have been validated for various cultures and languages, including Spanish $[13,17,20]$. Neuropathic pain should be identified using the tools suggested by the International Association for the Study of Pain (i.e., Lanss Pain Scale, DN4, Neuropathic Pain Questionnaire, painDETECT) [21,22].

Cancer patients should be monitored using validated multidimensional tools. Evaluations should be performed frequently in order to determine the efficacy of treatment. In other words, regardless of whether the intensity of pain decreases and functionality improves, the presence of new pain must be evaluated [13].

\section{Breakthrough cancer pain}

Breakthrough cancer pain (BTcP) was first defined by Portenoy and Hagen in 1990 as a "transitory exacerbation of pain experienced by the patient who has relatively stable and adequately controlled baseline pain" in patients undergoing long-term opioid treatment for cancer-related pain [23]. BTcP has been defined as an acute exacerbation of pain with sudden onset, short duration and moderate-to-high intensity in patients who experience stabilized baseline pain controlled with opioids $[24,25]$. The definition of $\mathrm{BTcP}$ varies by country. It is an English term with no literal translation in some languages, including Spanish. After the initial definition, Coluzzi defined episodic pain as comprising three categories of pain that are characterized by being transitory pain that appears on top of controlled baseline pain [26]. The three types of pain are as follows:

- Incidental pain, which is related to physical effort or specific movements and is somewhat predictable;

- BTcP, which is transitory pain that appears without a known trigger. It is generally moderate or severe, and onset is fast. It may be neuropathic, somatic, visceral or mixed [27]; 
- End-of-dose pain (also known as analgesic gaps), which appears before the following opioid dose is due to be administered, thus leading to inappropriate dosing intervals [28].

Therefore, the Task Force of Change Pain Latin America decided to classify episodic pain according to its triggering factors into three categories: incidental, breakthrough (BTcP) and end-of-dose pain (Table 1).

Despite this semantic variability, BTcP is frequently reported.

The prevalence of $\mathrm{BTcP}$ has proven difficult to establish owing to conceptual differences and heterogeneous methodologies in various publications. However, prevalence is reported to range from 40 to $80 \%$, and it is generally estimated that up to $75 \%$ of patients with well-controlled baseline pain can experience BTcP [30].

$\mathrm{BTcP}$ can be managed with a dose of rescue analgesic, an immediate-release opioid formulation or fast-acting drugs such as transmucosal fentanyl or fentanyl buccal tablets [31].

Fentanyl (buccal, sublingual, transmucosal, intranasal and gingival) is as close to an ideal drug to treat $\mathrm{BTcP}$ as possible, owing to its high analgesic power and lipophilicity. The dose must be titrated, and treatment should start with the lowest available dose before escalating in short steps until the minimum effective dose is reached [29,32]. Nevertheless, since these formulations are not available in many Latin American countries, the best option is fast-acting opioids, which are effective and may even be used as prophylaxis (in incidental pain).

Treatment should be multimodal to take account of the following:

- Management of reversible causes (orthesis, splints, cough suppressants and laxatives);

- Nonpharmacological measures: hot and cold massages, distraction and relaxation techniques, cognitive behavioral therapies and acupuncture. These therapies may be used before, during and after pharmacological therapy $[24,25,33]$.

Adequate management of $\mathrm{BTcP}$ remains challenging.

\section{Pharmacological treatment}

In 1986, the WHO published its analgesic ladder for cancer pain treatment and recommendations on the use of analgesics (Box 4). The analgesic ladder proposes 3 steps for the rational use of analgesics in the treatment of cancer pain. Step 1 requires the use of nonopioid analgesics for mild pain, step 2 recommends weak opioids for moderate pain and step 3 is based on strong opioids for severe pain. If necessary, adjuvant drugs can be used at each step. The flexibility of application of the ladder has proven particularly useful in countries where weak opioids are more widely available than strong opioids. There is no doubt that the WHO method has been hugely beneficial for the treatment of cancer pain throughout the world [34]. However, the ladder has been widely criticized for being too simplistic, lacking strong evidence of effectiveness and not being effective for quick pain control. However, when its guidelines are closely adhered to, pain can be controlled in up to $76 \%$ of cases [35]. In Latin America, the WHO guidelines have proven critical for justifying to local governments the essential role of opioids such as morphine and the need for an adequate supply. Furthermore, they show health professionals the importance of opioid management and decrease the fear of addiction and illegal abuse [35].

\section{Opioids}

Opioids are the cornerstone of cancer pain management. Nevertheless, in Latin America, there are still many barriers to appropriate use

\section{Table 1. Types of episodic pain.}

\begin{tabular}{|c|c|c|c|}
\hline Pain & Incident & Breakthrough & At the end of the dose \\
\hline Definition & $\begin{array}{l}\text { Transient and predictable pain that responds to a } \\
\text { voluntary stimulus } \\
\text { (standing, walking, moving on bed), } \\
\text { involuntary (sneezing, coughing), procedural (bed sores } \\
\text { healing, paracentesis, abscess drainage) and emotional }\end{array}$ & $\begin{array}{l}\text { Transient without known triggering } \\
\text { stimuli (or trigger factor), usually } \\
\text { severe, fast onset. Nociceptive origin, } \\
\text { neuropathic origin or both }\end{array}$ & $\begin{array}{l}\text { Occurs before the } \\
\text { administration of the } \\
\text { next dose }\end{array}$ \\
\hline Prevalence & $32-94 \%$ & $28-45 \%(29)$ & \\
\hline Cause & Bone metastasis (more frequent) & Tumor affecting nerve roots & $\begin{array}{l}\text { Inadequate control of } \\
\text { baseline chronic pain }\end{array}$ \\
\hline
\end{tabular}


Box 4. Recommendations for use of analgesics.

- Oral administration

- Administer at regular intervals

- Administer according to the intensity of pain

- Tailor dose

- Constant vigilance by physicians to detect even minor changes

Data taken from [36].

of these drugs owing to the low accessibility to and availability of opioids, restrictive laws and opiophobia. Given the wide interindividual variability in the response to a specific opioid, it is important to know the pharmacological differences between them. There is no proven evidence that one opioid agonist is better than another as first-line therapy [12,37].

Opioid-naive patients with moderate pain (nontolerant)

Traditionally, and according to the WHO recommendations, minor opioids (e.g., tramadol and codeine) have been used at this stage (Second step - WHO Analgesic Ladder).

\section{- Codeine}

Codeine is a weak opioid agonist that binds to mu receptors and is metabolized mainly by glucuronidation to morphine. Its function requires the presence of the hepatic isoenzyme CYP 2D6. However, the activity of this enzyme varies considerably between different ethnic groups. Consequently, when metabolized slowly, codeine is relatively ineffective; rapid metabolism could lead to overdose [12].

\section{- Tramadol}

Tramadol is considered a weak dual drug with basically central action and affinity for $\mu, \kappa$ and $\partial$ opioid receptors. It also increases monoaminergic activity at the level of the spinal cord by inhibiting reuptake of serotonin and noradrenaline, thus boosting its action. This mechanism of action makes it useful for nociceptive and neuropathic pain. Tramadol is well tolerated and has low addictive potential [38].

For several years now, it has been suggested in clinical trials that strong opioids can prove useful as first-line treatment, especially of terminal cancer pain [37]. Some organizations, such as the National Comprehensive Cancer Network (NCCN) currently recommend considering the option of low doses of strong opioids for this group of patients (Table 2) $[36,39,40]$.

\section{- Morphine}

The NCCN Guidelines (2015) recommend starting with immediate-release oral morphine or equivalents at $5-15 \mathrm{mg}$. If pain does not diminish or increases, the dose should be increased by $50-100 \%$. If the pain improves, the dose should be calculated for $24 \mathrm{~h}$ and divided into $4-6 \mathrm{~h}$ intervals [40]. In a recent randomized trial, Bandieri et al. [42] concluded that in patients with cancer and moderate pain, low-dose morphine significantly reduced the intensity of pain compared with weak opioids, with similarly good tolerability and an earlier effect.

The WHO analgesic ladder is currently under revision by a committee organized by the WHO.

\section{Severe pain}

The analgesic ladder indicates that in cases of severe pain, therapy can be initiated with a major opioid administered either orally or by the least invasive route. There are no differences between morphine, oxycodone and hydromorphone. Treatment typically starts with immediate-release doses every $4 \mathrm{~h}$. Nevertheless, surveys have shown that starting with extended-release formulations is equally effective. All titrations should be accompanied by immediate-release opioids as rescue doses or as needed $[6,30]$.

For urgent cases, the 2015 NCCN guidelines recommend starting with intravenous

Table 2. Opioids recommended for treatment of moderate pain cancer in opioid-naive patients.

\begin{tabular}{|lll|}
\hline Opioid & Type of opioid & Dose \\
Tramadol with or without paracetamol & Weak & $<400 \mathrm{mg} /$ day \\
\hline Codeine with or without paracetamol & Weak & $<360 \mathrm{mg} /$ day \\
\hline Morphine & Strong & $<30 \mathrm{mg} /$ day \\
Oxycodone with or without paracetamol & Strong & $<20 \mathrm{mg} /$ day \\
\hline Hydromorphone & Strong & $<4 \mathrm{mg} /$ day \\
\hline Data taken and modified from [41]. & & \\
\hline
\end{tabular}


morphine at $2-5 \mathrm{mg}$ every $15 \mathrm{~min}$. If pain does not decrease or increases, the dose should be increased by $50-100 \%$; if pain decreases, but remains severe, the same dose should be repeated, up to a maximum of three doses. If pain decreases, the same dose should be maintained for $24 \mathrm{~h}$, then changed to oral or transdermal administration [40].

\section{Pain management in tolerant patients}

A patient is deemed to be opioid-tolerant when he/she receives chronic opioid analgesia and, according to the recommendations of the US FDA, receives at least morphine $60 \mathrm{mg} /$ day, oxycodone $30 \mathrm{mg} /$ day, hydromorphone $8 \mathrm{mg} /$ day or any other opioid in equianalgesic doses [40].

These treatments may be maintained with any extended-release opioid (morphine, oxycodone, hydromorphone), methadone or tapentadol (oral) or fentanyl or buprenorphine transdermal patches, with addition of immediate-release formulations as needed [38].

The FDA had published a warning regarding the fentanyl transdermal patch, which is indicated exclusively for the management of persistent, moderate-to-severe chronic pain in opioid-tolerant patients who require a total daily opioid dose at least equivalent to transdermal fentanyl $25 \mu \mathrm{g} / \mathrm{h}$. Use of the fentanyl patch in nonopioid-tolerant patients has resulted in fatal respiratory depression [43]. In any case, it is paramount to be aware of the patients' comorbidities and preferences in order to determine the most suitable long-term opioid.

\section{- Methadone}

Methadone is a synthetic opioid used for the treatment of physical dependency and chronic pain. It is a mu receptor, opioid receptor agonist and an $\mathrm{N}$-methyl $\mathrm{D}$ aspartate antagonist. It blocks reuptake of norepinephrine and serotonin and has a long plasma half-life (15-60 h and up to $120 \mathrm{~h}$ ), which can increase the possibility of involuntary overdose. The morphinemethadone equivalent dose has not been clearly determined and depends on the previous dose of morphine.

Administration can be oral, rectal, nasal, sublingual, intravenous and epidural [12]. Given its analgesic properties, methadone is an excellent option for treatment of nociceptive pain and has proven very useful in cases of opioid tolerance [38]. In addition to its low cost, it is an ideal opioid for use in Latin America.
Methadone plays a key role in the management of cancer pain. Its several advantages over morphine and other opioids include the following:

\section{- Low cost;}

- Wide oral bioavailability (70-80\%);

- Long half-life;

- Inactive metabolites;

- Considerable analgesic potency.

Since methadone is metabolized in the liver, adverse effects may result from interactions with ketoconazole, omeprazole and serotonin reuptake inhibitors (fluoxetine, paroxetine and sertraline), all of which are frequently used in oncology. Some clinical studies suggest cardiovascular effects, such as prolongation of the QT interval or torsades de pointes. Given its long and variable half-life, potential interactions with several drugs, variability in conversion factors and the association with prolongation of the QT interval make methadone a drug with specific safety requirements [44].

A panel of experts from three medical societies recently published specific recommendations, as follows: the need to educate and counsel patients on methadone safety, use of electrocardiography to identify persons at greater risk for methadone-associated arrhythmia (prolongation of the QTc interval), careful initiation and titration of the dose, and diligent monitoring and follow-up [41].

\section{Prevention of adverse effects}

Adverse effects of opioids, such as constipation and nausea, may limit the dosing of opioids and lead to early discontinuation and inadequate analgesia. Nausea and vomiting occur in $15-40 \%$ of patients, and constipation affects up to $87 \%$ of terminally ill people who are receiving opioids [45].

\section{Table 3. Equianalgesic doses.}

\begin{tabular}{|lll|} 
Drug & Parenteral & Oral \\
Morphine & $10 \mathrm{mg}$ & $30 \mathrm{mg}$ \\
\hline Codeine & $100 \mathrm{mg}$ & $200 \mathrm{mg}$ \\
\hline Fentanyl & $0.1 \mathrm{mg}$ & \\
\hline Hydromorphone & $1.5 \mathrm{mg}$ & $7.5 \mathrm{mg}$ \\
\hline Oxycodone & $10 \mathrm{mg}$ & $20 \mathrm{mg}$ \\
\hline Tramadol & $100 \mathrm{mg}$ & $120 \mathrm{mg}$ \\
\hline Data taken and modified from $[36,47]$ & \\
\hline
\end{tabular}


Table 4. Conversion factors for parenteral opioids.

\begin{tabular}{|lll|}
\hline Drug & Conversion factor & Potency \\
\hline Sublingual buprenorphine & $60-100$ & More potent than morphine \\
\hline Hydromorphone & 7.5 & More potent than morphine \\
\hline Oxycodone & $1.5-2$ & More potent than morphine \\
\hline Morphine & 1 & Morphine \\
\hline Tapentadol & 3.3 & Less potent than morphine \\
\hline Tramadol & 4 & Less potent than morphine \\
\hline Codeine & 12 & Less potent than morphine \\
\hline Data taken from [47]. & & \\
\hline
\end{tabular}

Therefore, antiemetic therapy should be prescribed if necessary. Metoclopramide and haloperidol are the most commonly used drugs. The patient begins to tolerate the drug 3-5 days after starting treatment.

Patients taking opioids do not develop tolerance to constipation; therefore, treatment with laxatives should be maintained in the long term. There is no evidence that one laxative works better than another.

CNS-related adverse effects include sedation and dizziness, cognitive impairment and psychomotor alterations, as well as clonus and hyperexcitability. Sedation can be treated with psychostimulants such as methylphenidate, although it is sometimes necessary to rotate opioids $[12,36,40]$.

\section{Opioid rotation}

Opioid rotation is a strategy that enables one opioid to be switched for another based on conversion factors that make it possible to perform an approximate calculation of equivalent doses between the drugs. The objective of the strategy is to improve the results of analgesia and/or reduce adverse effects with as little risk as possible for the patient. Although many equianalgesic tables are available, the scientific evidence on which they are based is limited (nonrandomized descriptive studies) [46]. Tables 3-5 list equianalgesic doses.

\section{Table 5. Conversion factors for oral opioids}

\begin{tabular}{|lll|}
\hline Drug & Conversion factor & Potency \\
\hline Fentanyl & $68-100$ & More potent than morphine \\
\hline Buprenorphine & $30-40$ & More potent than morphine \\
\hline Morphine & 1 & Morphine \\
\hline Oxycodone & $1-1.5$ & Less potent than morphine \\
\hline Nalbuphine & 1 & Less potent than morphine \\
\hline Tramadol & 10 & Less potent than morphine \\
\hline Data taken from [47]. & & \\
\hline
\end{tabular}

Once calculated, the new dose must be decreased by $25-50 \%$ depending on the patient's clinical condition, because cross-tolerance to opioids is never $100 \%$ [ $47-49]$.

\section{Adjuvant analgesics}

Adjuvant analgesics work at different levels to relieve pain (Table 6). They are useful for management of neuropathic and bone pain.

The prevalence of neuropathic pain is unknown, although available data show it to be present in $30 \%$ of patients with cancer pain, thus making it a poor predictive biomarker of response to analgesics.

Given the lack of clinical trials on neuropathic cancer pain and specific cancer pain guidelines, guidelines for nononcologic pain have been extrapolated to cancer patients. If pain is severe at the beginning of treatment, opioids and neuromodulators must be initiated concurrently. Therapy should be initiated with one drug, which should be uptitrated according to the patient's response in order to determine adverse effects [52].

In many cases, it is necessary to combine drugs with different mechanisms of action in order to improve analgesia and decrease adverse effects [50]. Nevertheless, since pain is not relieved in $10-15 \%$ of patients, other strategies such as, radiotherapy [53], invasive procedures and nonpharmacological therapies must be considered $[38,45]$.

\section{Cancer management}

Pain relief can be optimized by combining cancer treatments (radiotherapy, radiopharmaceutical therapy, chemotherapy, hormone therapy, bisphosphonates and surgery) with pharmacological and nonpharmacological approaches [14,51,53-54].

\section{Interventional therapies}

It is thought that in up to $10 \%$ of patients with cancer pain, relief is not achieved with conventional analgesia, thus justifying the addition of interventional techniques. Interventional techniques are useful, particularly for pain that is difficult to manage. Some regimens have unbearable side effects despite providing appropriate analgesia. Such is the case of intrathecal drug delivery and epidural administration of opioids, which can be an alternative when pain cannot be controlled despite increasing the dose of or rotating opioids and the use of adjuvant drugs has been 


\begin{tabular}{|c|c|c|c|}
\hline Type of drug & Daily recommended dose & Route & Indications \\
\hline Antidepressants & $\begin{array}{l}\text { Amitriptyline } 10 \text { to } 25-150 \mathrm{mg} / \text { day } \\
\text { Nortriptyline } 25 \mathrm{mg} / \text { day } \\
\text { Desipramine } 10 \text { to } 25-150 \mathrm{mg} / \text { day } \\
\text { Venlafaxine } 37.5-150 \mathrm{mg} / \text { day } \\
\text { Duloxetine } 30-120 \mathrm{mg} / \text { day }\end{array}$ & Oral & Neuropathic pain \\
\hline Anticonvulsants & $\begin{array}{l}\text { Gabapentin } 1200-3600 \mathrm{mg} / \text { day } \\
\text { Pregabalin } 150-600 \mathrm{mg} / \text { day }\end{array}$ & Oral & Neuropathic pain \\
\hline Corticosteroids & Dexamethasone 4-24 mg/day & Oral/iv. & $\begin{array}{l}\text { Neuropathic, bone, visceral } \\
\text { pain, brain edema, spinal cord } \\
\text { compression }\end{array}$ \\
\hline Lidocaine & $\begin{array}{l}\text { Patches } 5 \% / \text { day } \\
\text { Bolus } 1-2 \mathrm{mg} / \mathrm{kg} \text { in } 15-30 \mathrm{~min} \text {. If effective, } 2 \mathrm{mg} / \mathrm{kg} / \mathrm{h}\end{array}$ & $\begin{array}{l}\text { Topical } \\
\text { iv. }\end{array}$ & Neuropathic pain \\
\hline NMDA antagonists & $\begin{array}{l}\text { Ketamine: } 0.04-0.3 \mathrm{mg} / \mathrm{kg} / \mathrm{h} \\
\text { Amantadine } \\
\text { Magnesium } 1 \mathrm{~g} / \text { day }\end{array}$ & $\begin{array}{l}\text { iv./oral/sc./sl./topical } \\
\text { Oral } \\
\text { iv. }\end{array}$ & $\begin{array}{l}\text { Neuropathic pain } \\
\text { Tolerance to opioids }\end{array}$ \\
\hline Bisphosphonates & $\begin{array}{l}\text { Pamidronate } 60-90 \mathrm{mg} \text { every } 2-4 \text { weeks } \\
\text { Zoledronic acid } 4 \mathrm{mg} \text { every } 3-4 \text { weeks } \\
\text { lbandronate } 6 \mathrm{mg} \times 3 \text { days, then every } 3-4 \text { weeks }\end{array}$ & iv. & Osteolytic bone pain \\
\hline
\end{tabular}

exhausted. This approach can be applied as long as it is tested successfully with a temporary catheter (intrathecal or epidural) and when survival is expected to be more than 6 months. Neurolytic blockade can be considered an adjuvant to drug therapy when the pain is refractory and life expectancy is less than 6 months. However, evidence is limited, and results with these techniques are operator-dependent and vary with the degree of disease progression. Celiac plexus block has been reported for upper abdominal visceral pain, especially which is associated with pancreatic cancer. In addition, superior hypogastric plexus block and ganglion impar block can prove useful in pelvic and perineal pain [55].

Other techniques include radiofrequency lesioning, spinal cord stimulation, vertebroplasty, kyphoplasty and botulinum toxin injections (a recently introduced approach). These may be used in cases of spasticity, radiationinduced fibrosis, cervical dystonia, headache and trigeminal neuralgia [12].

\section{Psychological, rehabilitative and integrative approaches to cancer pain}

The use of integrated nonpharmacological interventions (physical, cognitive and spiritual) may prove to be valuable additions to pharmacological therapy. These include the following:

- Physical measures (hot and cold massage, acupuncture and acupressure);
- Cognitive interventions aimed at giving the patient a sense of control over pain or the underlying disease;

- Breathing exercises, relaxation, mindfulness, imagery/hypnosis and other behavioral therapies.

Involving religious/spiritual advisors is essential for the comprehensive management of care. Spiritual needs should be routinely evaluated, and spiritual care should be a key component of pain management, with due respect to beliefs and cultures [14].

The above-mentioned measures are aimed at increasing the sense of control and wellbeing and at reducing the sense of impotence and helplessness, both in caregivers and family members [43].

\section{Conclusion}

In Latin America and the Caribbean, cancer pain management is a serious issue that has not been adequately resolved. The present guidelines can be used as support for clinicians and members of the government in their efforts to ensure widespread implementation of protocols in healthcare facilities throughout the region. It is clear that cancer pain management is complex and requires both teamwork and rational use of all available tools, depending on the characteristics of the pain and the individual patient. 


\section{Future perspective}

By the year 2030, approximately 1.7 million persons will have been diagnosed with cancer in Latin America, and 1 million people per year will die from the disease. Consequently major difficulties will arise when addressing the increasing morbidity and mortality associated with the disease. Consumption of opioids in Latin America is far below international levels, suggesting that pain management is inadequate in the region. The WHO guidelines are particularly important in Latin America, as they justify the use of morphine to local governments and consider methadone an essential medication.

The complex nature of cancer pain makes management difficult. Therefore, guidelines can act as support for clinicians and governments in their efforts to ensure implementation of protocols in the region.
Acknowledgements

The authors would like to thank Grïnenthal Services, Inc.

for their support with the logistics of our meeting.

\section{Disclosure}

None of the authors of this manuscript received any professional fees whatsoever from Grünenthal Services, Inc. Grünenthal Services, Inc. provided logistical support for the experts.

\section{Financial \& competing interests disclosure}

The authors have no relevant affliations or financial involvement with any organization or entity with a financial interest in or financial conflict with the subject matter or materials discussed in the manuscript. This includes employment, consultancies, honoraria, stock ownership or options, expert testimony, grants or patents received or pending, or royalties.

Editorial assistance was provided by Content Ed Net, Madrid, Spain, with funding from Grünenthal Services, Inc.

\section{References}

Papers of special note have been highlighted as: - of interest; $\bullet \bullet$ of considerable interest

1 Goss PE, Lee BL, Badovinac-Crnjevic T et al. Planning cancer control in Latin America and the Caribbean. Lancet Oncol. 14(5), 391-436 (2013).

- An important publication on the situation of cancer in Latin America and the Caribbean. The magnitude of the problem is enormous, since $54 \%$ of the inhabitants of the region do not have appropriate healthcare coverage. Most cancer patients are diagnosed in the advanced or terminal phase. Hence the particular relevance of palliative medicine and pain control.

2 UN. Older Persons in Latin America and the Caribbean: Situation and Policies. ECLAC Population Division - Latin American and Caribbean Demographic Centre(CELADE), Santiago, Chile (2003).

3 van den Beuken-van Everdingen MH, de Rijke JM, Kessels AG, Schouten HC, Van Kleef M, Patijn J. Prevalence of pain in patients with cancer: a systematic review of the past 40 years. Ann. Oncol. 18(9), 1437-1449 (2007).

4 Duthey B, Scholten W. Adequacy of opioid analgesic consumption at country, global, and regional levels in 2010, its relationship with development level, and changes compared with 2006. J. Pain Symptom Manage. 47(2), 283-297 (2014).

- Analysis of the consumption of opioids for different countries and regions that takes into account morbidity and the WHO Human Development Index compared with 2006. Most people have no access to opioids for pain relief in case of need; $66 \%$ of the world's population have no access, $10 \%$ have very low access, $4 \%$ moderate access and only $7.5 \%$ have adequate access. The lack of opioids is a major reason for the poor control of cancer pain.

5 Cleary J, De Lima L, Eisenchlas J, Radbruch L, Torode J, Chermy NI. Formulary availability and regulatory barriers to accessibility of opioids for cancer pain in Latin America and the Caribbean: a report from the Global Opioid Policy Initiative (GOPI). Ann. Oncol. 24(11), xi41-xi50 (2013).

6 Knudsen AK, Aass N, Fainsinger R et al. Classification of pain in cancer patients - a systematic literature review. Palliat. Med. 23(4), 295-308 (2009).

7 Haugen DF, Hjermstad MJ, Hagen N, Caraceni A, Kaasa S, European Palliative Care Research Collaborative (EPCRC). Assessment and classification of cancer breakthrough pain: a systematic literature review. Pain 149(3), 476-482 (2010).

8 Caraceni A, Portenoy RK. An international survey of cancer pain characteristics and syndromes. IASP Task Force on Cancer Pain. International Association for the Study of Pain. Pain 82(3), 263-274 (1999).

9 Caraceni A, Davies A, Poulain P, CortésFunes H, Panchal SJ, Fanelli G. Guidelines for the management of breakthrough pain in patients with cancer. J. Natl Compr. Canc. Netw. 11(Suppl. 1), S29-S36 (2013).

10 Narayana A, Katz N, Shillington AC et al. National Breakthrough Pain Study: prevalence, characteristics, and associations with health outcomes. Pain 156, 252-259 (2015).

11 International Association for the Study of Pain Breakthrough Pain in Cancer Patients. Pain Clinical Updates IASP (2006). http://iasp.files.cms-plus.com

12 Paice JA, Ferrell B. The management of cancer pain. CA Cancer J. Clin. 61(3), 157-182 (2011).

13 Scottish Intercollegiate Guidelines Network Control of pain in patients with cancer (2007). www.sign.ac.uk

14 British Pain Society. Cancer Pain Management 2010. www.britishpainsociety.org

15 Cid J, Acuña JP, De Andrés J, Díaz L, Gómez-Caro L. ¿QQué y cómo evaluar al paciente con dolor crónico? Evaluación del paciente con dolor crónico. Rev. Med. Clin. Condes. 25(4), 687-697 (2014).

16 Serrano Atero MS, Caballero J, Cañas A, Garcia-Saura PL, Serrano-Alvarez, Prieto J. Valoración del dolor (II). Rev. Soc. Esp. Dolor. 9, 109-121 (2002).

17 Kumar SP. Utilization of brief pain inventory as an assessment tool for pain in patients with cancer: a focused review. Indian J. Palliat. Care 17(2), 108-115 (2011). 
18 Miró J. Evaluación de la intensidad del dolor en el paciente con cáncer. Psicooncología 9(2-3), 393-401 (2012).

19 Ngamkham S, Vincent C, Finnegan L, Holden JE, Wang ZJ, Wilkie DJ. The McGil Pain Questionnaire as a multidimensional measure in people with cancer: an integrative review. Pain Manag. Nurs. 13(1), 27-51 (2012).

20 Badia X, Muriel C, Gracia A et al. Validación española del cuestionario Brief Pain Inventory en pacientes con dolor de causa neoplásica. Med. Clin. (Barc) 120(2), 52-59 (2003).

21 Bennett MI, Rayment C, Hjermstad M, Aass N, Caraceni A, Kaasa S. Prevalence and aetiology of neuropathic pain in cancer patients: a systematic review. Pain 153(2), 359-365 (2012)

22 Mercadante S, Gebbia V, David F et al. Tools for identifying cancer pain of predominantly neuropathic origin and opioid responsiveness in cancer patients. J. Pain 10(6), 594-600 (2009).

23 Portenoy RK, Hagen NA. Breakthrough pain: definition, prevalence and characteristics. Pain 41, 273-281 (1990).

24 Davies AN, Dickman A, Reid C, Stevens AM, Zeppetella G. Science Committee of the Association for Palliative Medicine of Great Britain and Ireland. The management of cancer-related breakthrough pain recommendations of a task group of the Science Committee of the Association for Palliative Medicine of Great Britain and Ireland. Eur. J. Pain 13(4), 331-338 (2009).

25 Portenoy RK, Forbes K, Lussier D, Hangs G. Difficult pain problems: an integrated approach. In: Oxford Textbook of Palliative Medicine (3rd Edition). Doyle D, Hanks G, Cherny N, Calmen K, (Eds). Oxford University Press, Oxford, UK, 1438-1458 (2004).

26 Coluzzi PH. Cancer pain management: newer perspectives on opioids and episodic pain. Am. J. Hosp. Palliat. Care 15(1), 13-22 (1998).

27 Nabal M, Madrid F. Dolor episódico: definición, etiología y epidemiología. Rev. Soc. Esp. Dolor 9, 88-93 (2002).

28 Pergolizzi JV, Gharibo C, Ho KY. Treatment considerations for cancer pain: a global perspective. Pain Pract. 15 (8), 778-792 (2015).

-. Cancer pain is common, untreated and feared by patients. In 2013, an expert panel reviewed various aspects of cancer pain, such as the consequences of not treating it, functional impairment and distress. The authors review specific regimens for the treatment of pain in 'special populations' (elderly persons, frail persons, patients with several comorbidities, patients with terminal organ failure).

29 Escobar Álvarez Y, Biete i Solà A, Camba Rodríguez $\mathrm{M}$ et al. Diagnóstico y tratamiento del dolor irruptivo oncológico: recomendaciones de consenso. Rev. Soc. Esp. Dolor 21(2), 97-105 (2014).

30 Mercadante S. Breakthrough pain in cancer patients: prevalence, mechanisms and treatment options. Curr. Opin. Anaesthesiol. 28(5), 559-564 (2015).

- Breakthrough cancer pain $(\mathrm{BTcP})$ is a serious problem in patients with cancer who are receiving treatment with opioids. Subgroups of patients with BTcP have been identified. Various modalities of drug therapy are available. BTcP remains a clinical and therapeutic challenge.

31 Working Group Nientemale DEI, Vellucci R, Fanelli G et al. What to do, and what not to do, when diagnosing and treating breakthrough cancer pain (BTcP): expert opinion. Drugs 76(3), 315-330 (2016).

32 Zeppetella G, Ribeiro MD. Opioids for the management of the breakthrough (episodic) pain in cancer patients. Cochrane Database Syst. Rev. 25(1), CD004311 (2006).

33 Zeppetella G. Breakthrough pain in cancer patients. Clin. Oncol. 23(6), 393-398 (2011)

34 Eisenberg E, Marinangeli F, Birkhahn J, Paladini A, Varrassi G. Time to modify the WHO analgesic ladder? Pain Clinical Updates (IASP Press) 13(5), 1-4 (2005).

35 Mair J. Is the $\mathrm{WHO}$ analgesic ladder active or archaic? Eur. J. Palliat. Care 15(4), 162-165 (2008).

36 Caraceni A, Hanks G, Kaasa S et al. Use of opioid analgesics in the treatment of cancer pain: evidence-based recommendations from the EAPC. Lancet Oncol. 13, e58-e68 (2012).

37 Marinangeli F, Ciccozzi A, Leonardis $\mathrm{M}$ et al. Use of strong opioids in advanced cancer pain: a randomized trial. J. Pain Symptom Manage. 27, 409-416 (2004).

38 Vadalouca A, Raptis E, Moka E, Ais P, Sykioti P, Siafaka I. Pharmacological treatment of neuropathic cancer pain: a comprehensive review of the current literature. Pain Pract. 12(3), 219-251 (2012).

39 Cleary JF. The pharmacologic management of cancer pain. J. Palliat. Med. 10(6), 1369-1394 (2007).

40 National Comprehensive Cancer Network NCCN (2015). Clinical Practice Guidelines in Oncology (NCCN Guidelines Adult
Cancer Pain Version 2).

www.ncen.org

- The National Comprehensive Cancer Network (NCCN) is an alliance of 27 of the main cancer centers from throughout the world. It has developed Clinical Practice Guidelines in Oncology $\left(\mathrm{NCCN}^{\circledast}\right)$ and reports on management, including pain relief and symptomatic support, based on evidence and oriented by consensus toward the greatest benefit for patients.

41 Chou R, Cruciani RA, Fiellin DA et al. Methadone safety: a clinical practice guideline from the American Pain Society and College on Problems of Drug Dependence, in collaboration with the Heart Rhythm Society. J. Pain 15(4), 321-337 (2014).

42 Bandieri E, Romero M, Ripamonti CI et al. Randomized trial of low-dose morphine versus weak opioids in moderate cancer pain. J. Clin. Oncol. 34(5), 436-442 (2016).

43 US Food and Drug Administration. Information for Healthcare Professionals: Fentanyl Transdermal System (marketed as Duragesic and generics) - 12/21/2007 Update. www.fda.gov

44 Good P, Afsharimani B, Movva R, Haywood A, Khan S, Hardy J. Therapeutic challenges in cancer pain management: a systematic review of methadone. J. Pain Palliat. Care Pharmacother. 28(3), 197-205 (2014).

45 Vignaroli E, Bennett MI, Nekolaichuk C et al. Strategic pain management: the identification and development of the IAHPC opioid essential prescription package. J. Palliat. Med. 15(2), 186-191 (2012).

46 Afsharimani B, Kindl K, Good P, Hardy J. Pharmacological options for the management of refractory cancer pain-what is the evidence? Support Care Cancer 23(5), 1473-1481 (2015).

- Refractory cancer pain, which does not respond to standard opioid therapy or co-analgesics, affects $10-20 \%$ of patients. Treatment options include opioids, nonopioids and co-analgesics (paracetamol, nonsteroidal anti-inflammatory drugs, antidepressants and antiepileptic drugs), NMDA receptor antagonists, cannabinoids, lidocaine and corticosteroids. The evidence in favor of a benefit of any of these agents is weak, and each additional agent increases the risk of adverse effects.

47 Hernández Ortiz A. Equianalgésica y rotación de opioides en el perioperatorio. Revista Mexicana de Anestesiología 38(1), 172-174 (2015). 
48 Fine PG, Portenoy RK, Ad Hoc Expert Panel on Evidence Review and Guidelines for Opioid Rotation. Establishing "best practices" for opioid rotation: conclusions of an expert panel. J. Pain Symptom Manage. 38, 418-425 (2009).

49 Mercadante S, Caraceni A. Conversion ratios for opioid switching in the treatment of cancer pain: a systematic review. Palliat. Med. 25(5), 504-515 (2011).

50 Davis M, Walsh D, Lagman R, LeGrand SB. Controversies in pharmacotherapy of pain management. Lancet Oncol. 6(9), 696-704 (2005).

51 Aapro M, Saad F, Costa L. Optimizing clinical benefits of bisphosphonates in cancer patients with bone metastases. Oncologist 15(11), 1147-1158 (2010).
52 Smith TJ, Saiki CB. Cancer pain management. Mayo Clin. Proc. 90 (10), 1428-1439 (2015).

-• Despite increasing interest in cancer pain and efforts to improve treatment thereof, pain continues to be poorly managed in almost half of all cancer patients. The authors propose an exhaustive evaluation of cancer pain and current treatment options (opioids, adjuvant drugs, interventional techniques and nondrug therapy).

53 Lutz S, Berk L, Chang E et al. Palliative radiotherapy for bone metastases: an ASTRO evidence-based guideline. Int. J. Radiat. Onco. Biol. Phys. 79(4), 965-976 (2011).

54 Roqué I Figuls M, Martinez-Zapata MJ, Scott-Brown M, Alonso-Coello P. Radioisotopes for metastatic bone pain.
Cochrane Database Syst. Rev. (7), CD003347 (2011).

55 Ripamonti CI, Santini D, Maranzano E, Berti M, Roila F, ESMO Guidelines Working Group. Management of cancer pain: ESMO Clinical Practice Guidelines. Ann. Oncol. 23(Suppl. 7), vii139-vii154 (2012).

- Guidelines of the European Society for Medical Oncology (ESMO) for the management of cancer pain. The guidelines include a review of the incidence, evaluation of management of pain and adverse effects of analgesics. The review of the data shows that only a few randomized controlled trials have been performed in patients with cancer pain. Therefore, the level of evidence and grade of recommendation are limited. 